\title{
Use of argatroban: Experiences in continuous renal replacement therapy in critically ill patients after cardiac surgery
}

\author{
Matthias Klingele, MD, ${ }^{a}$ Hagen Bomberg, MD, ${ }^{\mathrm{b}, \mathrm{c}}$ Anne Lerner-Gräber, $\mathrm{MD},{ }^{\mathrm{a}}$ Danilo Fliser, MD, \\ Aaron Poppleton, MD, ${ }^{a}$ Hans J. Schäfers, MD, ${ }^{b}$ and Heinrich V. Groesdonk, MD ${ }^{b, c}$
}

\begin{abstract}
Objectives: Acute kidney injury requiring renal replacement therapy (RRT) is a common complication after cardiac surgery, complicated by suspected or proven heparin-induced thrombocytopenia (type II). The present study evaluated the use of argatroban as an anticoagulant during continuous RRT in the early period after cardiac surgery. Argatroban was compared with unfractionated heparin (UH) with respect to bleeding complications and the effectiveness of anticoagulation.
\end{abstract}

Methods: Patients requiring RRT after cardiac surgery from March 2007 to June 2009 were identified. The effectiveness of anticoagulation was measured indirectly by the duration of dialysis filter use. Bleeding was defined as clinical signs of blood loss or the need for transfusion.

Results: Of 94 patients, 41 received argatroban, $27 \mathrm{UH}$, and 26 required conversion from UH to argatroban. In all 3 subgroups, RRT was begun within a median postoperative period of 2.0 days. Similar levels of anticoagulation were achieved with the duration of the circuit and filter changed an average of 1.1 times daily during RRT. Liver function was comparable in all patients. Neither clinically relevant signs of bleeding nor significant differences in the hemoglobin levels or a requirement for transfusion were noted. However, the Simplified Acute Physiology Score II values during dialysis and mortality were significantly greater in the patients initially receiving argatroban compared with those who received UH alone (54 \pm 2 vs $43 \pm 3$, $P<.001 ; 71 \%$ vs $44 \%, P=.04)$.

Conclusions: Argatroban can provide effective anticoagulation in postoperative cardiac patients receiving continuous RRT. Close monitoring and dose titration resulted in a comparable risk of bleeding for anticoagulation with both argatroban and heparin, regardless of the disease severity or impaired hepatic function. (J Thorac Cardiovasc Surg 2014;147:1918-24)

Acute kidney injury (AKI) is a common complication after cardiac surgery. Depending on the definition of AKI, the incidence has varied from $0.3 \%$ to $29.7 \%$, with a need for renal replacement therapy (RRT) occurring in approximately $5 \%$ of cases. ${ }^{1-3}$

Unfractionated heparin (UH) has remained the anticoagulant of choice during RRT, because it is inexpensive, ubiquitously available, simple to dose and monitor, and has a known antidote in cases of bleeding. ${ }^{4}$ However, heparin is contraindicated in certain situations, in particular, if heparin-induced thrombocytopenia (HIT) type II (HIT II)

From the Departments of Internal Medicine, Nephrology, and Hypertension, ${ }^{a}$ Thoracic and Cardiovascular Surgery, ${ }^{\mathrm{b}}$ and Anaesthesiology, Intensive Care, and Pain Therapy, ${ }^{\mathrm{c}}$ Saarland University Hospital, Homburg/Saar, Germany.

Disclosures: Dr Klingele received speaker fees from Abbott, Baxter, Fresenius Medical Care, and Mitsubishi Pharm, and Dr Groesdonk received speaker fees from Mitsubishi Pharma. All other authors have nothing to disclose with regard to commercial support.

Received for publication July 9, 2013; revisions received Oct 22, 2013; accepted for publication Nov 15, 2013; available ahead of print Jan 31, 2014.

Address for reprints: Matthias Klingele, MD, Department of Internal Medicine IV, Nephrology, and Hypertension, Saarland University Hospital, Building 40.2, Kirrbergerstrasse, Homburg/Saar 66421, Germany (E-mail: Matthias.Klingele@ uks.eu).

$0022-5223 / \$ 36.00$

Copyright (C) 2014 by The American Association for Thoracic Surgery

http://dx.doi.org/10.1016/j.jtcvs.2013.11.051 is suspected or proved. HIT is an important and increasingly recognized antibody-mediated complication of heparin therapy occurring in approximately $0.5 \%$ to $5 \%$ of patients receiving heparin for $\geq 5$ days. ${ }^{5}$ Patients undergoing cardiac surgery are at particular risk. Everett and colleagues ${ }^{6}$ reported that the postoperative prevalence of heparin/platelet factor 4 antibodies was as great as $22.4 \%$ and that thromboembolic events occurred in $8.8 \%$ of patients with negative antibodies. This requires an alternative method of anticoagulation (eg, argatroban). ${ }^{7,8}$ Argatroban is a synthetic direct thrombin inhibitor derived from L-arginine, ${ }^{9}$ with elimination principally via the hepatic system, ${ }^{10}$ avoiding dose adjustment concerns in patients with renal insufficiency. Furthermore, the development of antibodies or cross-reactivity resulting in HIT II has not been described during argatroban therapy. ${ }^{11}$ Concerns exist, however, regarding the critically ill, in particular those with hepatic insufficiency in whom the half-life for elimination is increased, rendering monitoring and dose adjustment difficult. $^{8,12}$ This could increase the potential risk of severe bleeding complications.

In critically ill patients with AKI requiring RRT, the risk of bleeding complications within the early postoperative period increases owing to the anticoagulation required to 


$$
\begin{aligned}
& \text { Abbreviations and Acronyms } \\
& \text { AKI }=\text { acute kidney injury } \\
& \text { HIT }=\text { heparin-induced thrombocytopenia } \\
& \text { HIT II }=\text { HIT type II } \\
& \text { RRT }=\text { renal replacement therapy } \\
& \text { SAPS }=\text { Simplified Acute Physiology Score } \\
& \text { UH }=\text { unfractionated heparin }
\end{aligned}
$$

prevent blood clotting in the extracorporeal dialysis circuit. Moreover, in cases of continuous RRT, anticoagulant accumulation can occur over time. Data on the use of argatroban within this specific patient population are sparse. ${ }^{13-15}$ The aim of the present study was to evaluate the use of argatroban as an anticoagulant during continuous RRT for critically ill patients with AKI requiring RRT during the early period after cardiac surgery and compare it with the standard practice anticoagulation using heparin.

\section{METHODS \\ Patients}

All cases of RRT performed from March 2007 to June 2009 within an intensive care setting at the University Hospital of Saarland were retrospectively analyzed. The institutional review board (ethical committee of the Saarland, Germany, 233/11) approved the present study.

Within the study period, 104 patients required RRT in intensive care unit after cardiac surgery. Ten patients were excluded from the analysis because their anticoagulation regimen for continuous RRT required conversion on several occasions from heparin to argatroban or citrate. Data were collected by retrospective medical chart review for all patients undergoing continuous RRT. RRT was initiated in cases of AKI with blood urea nitrogen levels $>100 \mathrm{mg} / \mathrm{dL}$ or complications such as volume overload or hyperkalemia became life-threatening and could not be corrected by conservative treatment. Postoperative AKI was defined on the basis of the Acute Kidney Injury Network criteria. ${ }^{16}$ All patients received continuous venovenous hemodialysis with titration of either UH or argatroban for anticoagulation. Argatroban was given in cases of proven or clinically suspected HIT II. ${ }^{17}$ Clinical suspicion of HIT was determined by a persistently low or rapid decline in the platelet count or evidence of thrombosis or embolism as suggested by Lo and colleagues. ${ }^{18}$

\section{Study Groups}

Three subgroups were defined: group 1, patients receiving argatroban ( $\mathrm{n}=41$ ); group 2, patients receiving heparin throughout the entire observation period $(\mathrm{n}=27)$; and group 3 , patients requiring conversion from UH to argatroban $(n=26)$. Conversion to argatroban was in line with current recommendations suggesting lower dose argatroban for critically ill patients, in particular patients with impaired hepatic function or after cardiac surgery. ${ }^{8,15,19}$ The initial argatroban dose was $0.25 \mu \mathrm{g} / \mathrm{kg} / \mathrm{min}$. The subsequent dosage was titrated according to the activated partial thromboplastin time (60-90 seconds) measured within the extracorporeal circuit. Similarly, anticoagulation with UH was achieved by an initial bolus and subsequent continuous infusion to maintain the activated partial thromboplastin time at 60 to 90 seconds.

\section{Treatment and Measurements}

The effectiveness of anticoagulation was measured indirectly by the duration of dialysis filter use. Because the filters were changed routinely every 24 hours, the requirement for $>1$ filter daily indicated ineffective anticoagulation resulting in filter clotting.

Bleeding during anticoagulant therapy was defined as clinical bleeding signs (eg, postoperative wound bleeding or an increased postoperative drain volume) or the need for transfusion. The need for transfusion of erythrocytes was defined by hemoglobin $<9.5 \mathrm{~g} / \mathrm{dL}$, independent of the presence of signs of bleeding. Total erythrocyte transfusion requirements during the postoperative dialysis period in intensive care were measured and divided by the days of RRT, described as the erythrocyte concentrate/day of RRT. The need for platelet transfusion was defined as thrombocytopenia $<20,000 / \mu \mathrm{L}$ without active bleeding or $<50,000 / \mu \mathrm{L}$ with signs of active bleeding. The total number of platelet transfusions during the dialysis period in intensive care was measured and divided by the days of RRT, depicted as the number of platelet transfusions/day of RRT. Additional parameters considered included morbidity (Simplified Acute Physiology Score [SAPS] II) and outcomes (length of intensive care and hospital stay, duration of artificial ventilation, and mortality). The biochemical values were obtained from routine blood samples analyzed within an onsite clinical laboratory.

\section{Statistical Analysis}

All data are presented as the mean \pm standard error of the mean. Data analysis was performed using SPSS Statistics, version 19 (IBM, Ehningen, Germany). An initial comparison between the groups regarding the dichotomous variables was performed using chi-square tests. Student $t$ tests were performed for continuous variables to compare the differences among the groups (Welch's $t$ tests in the case of inhomogeneous variances). Two-sided $P$ values were computed.

\section{RESULTS \\ Patients}

Of the 94 patients, $41(43.6 \%)$ received argatroban, 27 $(28.7 \%)$ received $\mathrm{UH}$, and $26(27.7 \%)$ were converted from UH to argatroban. In all 3 subgroups, dialysis was begun within a median postoperative period of 2.0 days. At the initiation of RRT, no significant differences were noted in the distribution of gender, age, EuroSCORE II, or SAPS II scores (Table 1) among the 3 groups.

\section{Biochemical Markers at Initiation of Hemodialysis}

The values for biochemical markers obtained at admission and at the initiation of RRT did not differ significantly between the argatroban and UH groups, inclusive of platelet count, markers of renal function (serum urea or creatinine), and markers of hepatic function (bilirubin, cholinesterase, and albumin; Table 1). When RRT was started postoperatively, the hemoglobin level was comparable but significantly greater statistically in the patients treated with argatroban $(10.8 \mathrm{~g} / \mathrm{dL})$ than in those receiving $\mathrm{UH}(10.1 \mathrm{~g} / \mathrm{dL})$ exclusively. Overall, 3 patients had pre-existing liver disease ( 2 with Child A, 1 with Child B). None of these 3 patients had received argatroban.

\section{Results During Hemodialysis}

Comparing anticoagulation with argatroban and UH, no significant differences in hemoglobin levels were noted during the first 3 days of RRT (Figure 1). Furthermore, 
TABLE 1. Basic characteristics

\begin{tabular}{|c|c|c|c|c|c|c|}
\hline \multirow[b]{2}{*}{ Characteristic } & \multirow{2}{*}{$\begin{array}{c}\text { Argatroban } \\
(\text { group } 1 ; n=41)\end{array}$} & \multirow{2}{*}{$\begin{array}{c}\text { Heparin } \\
(\text { group 2; } \mathbf{n}=27)\end{array}$} & \multirow{2}{*}{$\begin{array}{c}P \text { value } \\
\text { (group } 1 \text { vs 2) } \\
\end{array}$} & \multirow{2}{*}{$\begin{array}{l}\text { Heparin to argatroban } \\
\quad(\text { group } 3 ; n=26)\end{array}$} & \multicolumn{2}{|c|}{$P$ value } \\
\hline & & & & & Group 1 vs 3 & Group 2 vs 3 \\
\hline \multicolumn{7}{|l|}{ Before surgery } \\
\hline Male gender (n) & $34(83)$ & $18(67)$ & .15 & $14(54)$ & $.01 *$ & .41 \\
\hline Age (y) & $74 \pm 9$ & $70 \pm 10$ & .10 & $73 \pm 10$ & .15 & .85 \\
\hline Weight $(\mathrm{kg})$ & $83 \pm 3$ & $77 \pm 3$ & .13 & $78 \pm 3$ & .21 & .84 \\
\hline Size $(\mathrm{cm})$ & $170 \pm 1$ & $170 \pm 1$ & .76 & $167 \pm 2$ & .15 & .09 \\
\hline EuroSCORE & $10.8 \pm 0.7$ & $9.3 \pm 0.8$ & .18 & $10.8 \pm 0.7$ & .96 & .013 \\
\hline NYHA class & $3.0 \pm 0.1$ & $3.2 \pm 0.1$ & .23 & $3.1 \pm 0.1$ & .68 & .44 \\
\hline Hemoglobin (g/dL) & $12.9 \pm 0.3$ & $12.2 \pm 0.3$ & .14 & $12.5 \pm 0.3$ & .047 & .51 \\
\hline Creatinine (mg/dL) & $1.7 \pm 0.1$ & $2.1 \pm 0.4$ & .27 & $2.1 \pm 0.4$ & .19 & .95 \\
\hline Urea $(\mathrm{mg} / \mathrm{dL})$ & $75 \pm 7$ & $75 \pm 11$ & .96 & $66 \pm 6$ & .32 & .47 \\
\hline INR & $1.2 \pm 0.1$ & $1.1 \pm 0.1$ & .51 & $1.1 \pm 0.1$ & .49 & .93 \\
\hline Bilirubin & $0.7 \pm 0.1$ & $1.4 \pm 0.4$ & .10 & $0.9 \pm 0.1$ & .15 & .21 \\
\hline \multicolumn{7}{|l|}{ Comorbidity } \\
\hline Atrial fibrillation & $15(37)$ & $6(22)$ & .29 & $1(4)$ & $.03 *$ & .10 \\
\hline Arterial hypertension & $38(93)$ & $20(74)$ & .08 & $23(89)$ & .67 & .29 \\
\hline Coronary artery disease & $31(76)$ & $17(63)$ & .29 & $16(62)$ & .28 & 1 \\
\hline Pulmonary hypertension & $9(22)$ & $7(26)$ & .77 & $14(54)$ & $.01 *$ & .05 \\
\hline Status after stroke & $5(12)$ & $0(0)$ & .15 & $6(23)$ & .32 & $.01 *$ \\
\hline Diabetes & $12(29)$ & $7(26)$ & 1 & $9(35)$ & .79 & .56 \\
\hline Liver disease & $0(0)$ & $3(11)$ & .06 & $0(0)$ & 1 & .24 \\
\hline \multicolumn{7}{|l|}{ Intraoperative } \\
\hline \multicolumn{7}{|l|}{ Procedure type } \\
\hline Emergent or urgent & $3(7)$ & $0(0)$ & .27 & $1(4)$ & 1 & .49 \\
\hline CABG & $24(59)$ & $17(63)$ & .80 & $15(58)$ & 1 & .78 \\
\hline Valve operation & $23(56)$ & $13(48)$ & .62 & $19(73)$ & .2 & .09 \\
\hline Combination surgery & $14(34)$ & $7(26)$ & .59 & $14(54)$ & .13 & .05 \\
\hline Redo CABG and/or valve & $11(27)$ & $4(15)$ & .37 & $5(19)$ & .57 & .73 \\
\hline Operation time (min) & $220 \pm 11$ & $227 \pm 17$ & .70 & $214 \pm 17$ & .75 & .57 \\
\hline CPB time (min) & $112 \pm 8$ & $106 \pm 11$ & .66 & $117 \pm 14$ & .70 & .53 \\
\hline AXC time (min) & $56 \pm 3$ & $62 \pm 5$ & .34 & $59 \pm 6$ & .71 & .70 \\
\hline IABP & $8(20)$ & $4(15)$ & .75 & $5(19)$ & 1 & .73 \\
\hline \multicolumn{7}{|l|}{ Before hemodialysis } \\
\hline SAPS II & $44 \pm 2$ & $41 \pm 3$ & .43 & $44 \pm 2$ & .90 & .49 \\
\hline \multicolumn{7}{|l|}{ Laboratory markers } \\
\hline Hemoglobin (g/dL) & $10.8 \pm 0.2$ & $10.1 \pm 0.2$ & $.03^{*}$ & $10.2 \pm 0.2$ & .07 & .61 \\
\hline Blood platelets (n) & $106 \pm 12$ & $118 \pm 14$ & .53 & $84 \pm 12$ & .21 & .07 \\
\hline Creatinine (mg/dL) & $3.2 \pm 0.2$ & $3.1 \pm 0.3$ & .87 & $2.6 \pm 0.3$ & .15 & .30 \\
\hline Urea $(\mathrm{mg} / \mathrm{dL})$ & $120 \pm 9$ & $108 \pm 11$ & .43 & $82 \pm 8$ & $.004 *$ & .06 \\
\hline Calcium (mmol/L) & $2.2 \pm 0.1$ & $2.2 \pm 0.1$ & .92 & $2.3 \pm 0.1$ & .11 & .06 \\
\hline Bilirubin & $2.9 \pm 0.3$ & $3.2 \pm 0.9$ & .15 & $1.5 \pm 0.2$ & .17 & .05 \\
\hline Cholinesterase (kU/L) & $2.9 \pm 0.1$ & $3.6 \pm 0.4$ & .09 & $3.5 \pm 0.3$ & $.04 *$ & .84 \\
\hline Albumin $(\mathrm{g} / \mathrm{L})$ & $23 \pm 1$ & $26 \pm 1$ & $.02 *$ & $25 \pm 1$ & .28 & .26 \\
\hline \multicolumn{7}{|l|}{ Outcome } \\
\hline Maximum SAPS II & $54 \pm 2$ & $43 \pm 3$ & $<.001^{*}$ & $55 \pm 2$ & .78 & $<.001^{*}$ \\
\hline Mechanical ventilation (h) & $276 \pm 35$ & $239 \pm 57$ & .56 & $348 \pm 65$ & .29 & .21 \\
\hline LOS ICU (d) & $11 \pm 1$ & $8 \pm 2$ & .16 & $16 \pm 4$ & .16 & .07 \\
\hline LOS hospital (d) & $19 \pm 2$ & $28 \pm 4$ & $.04 *$ & $29 \pm 5$ & .05 & .87 \\
\hline 30-d mortality & $29(71)$ & $12(44)$ & $.04 *$ & $14(54)$ & .20 & .59 \\
\hline Total sets $(\mathrm{n})$ & $7 \pm 1$ & $4 \pm 1$ & $<.001^{*}$ & $11 \pm 2$ & $.007^{*}$ & $<.001^{*}$ \\
\hline Sets/day of dialysis (n) & $1.1 \pm 0.1$ & $1.1 \pm 0.1$ & .56 & $1.1 \pm 0.1$ & .35 & .33 \\
\hline
\end{tabular}

Data presented as mean \pm standard deviation or $\mathrm{n}(\%) . N Y H A$, New York Heart Association; INR, international normalized ratio; $C A B G$, coronary artery bypass grafting; $C P B$, cardiopulmonary bypass; $A X C$, aortic crossclamp; IABP, intra-aortic balloon pump; SAPS, Simplified Acute Physiology Score; $L O S$, length of stay; ICU, intensive care unit. *Statistically significant. 

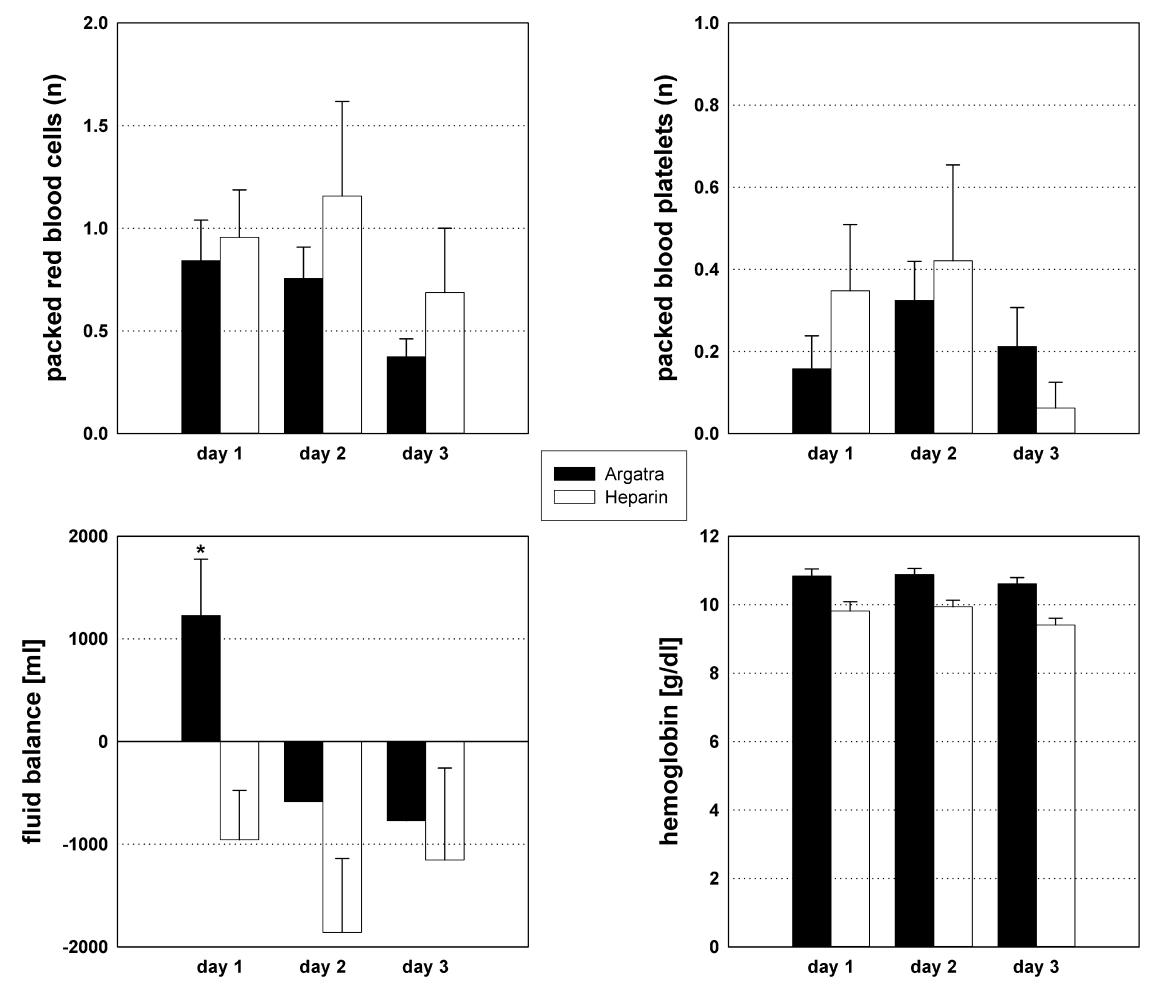

FIGURE 1. Need for transfusion, fluid balance, and hemoglobin within the first 3 days of continuous venovenous hemodialysis in patients receiving heparin or argatroban.

no significant differences were found in erythrocyte or platelet transfusion requirements (Figure 1). The fluid balance at day 1 of RRT was significantly higher in patients receiving argatroban compared with heparin $(1228 \pm 548$ vs $-957 \pm 481 ; P<.01 ;$ Figure 1$)$. No significant difference was noted during the subsequent 2 days of RRT.

Anticoagulation with argatroban compared with UH and conversion from UH to argatroban during RRT resulted in no significant difference in hemoglobin levels (Figure 2). No significant differences in the erythrocyte concentrate or platelet transfusion requirements were noted among the 3 groups during the observation period (Figure 2). However, the duration of dialysis was significantly longer in patients receiving argatroban and in those converted from $\mathrm{UH}$ to argatroban compared with those receiving $\mathrm{UH}$ alone $(6.5 \pm 0.7$ and $10.1 \pm 1.3$ vs $3.2 \pm 0.5 ; P<.001$; Figure 2). Transfusion requirements per day with erythrocytes or platelets before and after conversion from UH to argatroban in group 3 were comparable (Table 2). Similar levels of anticoagulation were achieved among all 3 groups, with the dialysis circuit and filter changed an average of 1.1 times per day of RRT (Table 1).

\section{Outcome Parameters}

The maximal SAPS II scores during dialysis were significantly elevated in group 1 (argatroban) and group 3 (conversion from UH to argatroban) compared with group 2 (UH; $54 \pm 2$ and $55 \pm 2$ vs $43 \pm 3 ; P<.001$; Table 1 ). Patients receiving argatroban had higher levels of mortality than patients receiving $\mathrm{UH}$ alone. However, this was only statistically significant for patients starting with argatroban $(44 \%$ vs $71 \%)$. No mortalities secondary to bleeding complications occurred. The differences in mechanical ventilation, length of intensive care or hospital stay, and 30-day mortality were not statistically significant (Table 1) among all 3 groups.

\section{DISCUSSION}

The choice of postoperative anticoagulation for patients with AKI requiring RRT has been difficult owing to the significant risk of bleeding. It has been proposed that this risk might be greater with argatroban than with $\mathrm{UH}$, with impaired hepatic function in critically ill patients potentially prolonging the half-life of argatroban. ${ }^{8,15}$ The absence of a readily available antidote adds additional concern. The present retrospective study investigated whether the risk of bleeding complications in patients with AKI requiring RRT after cardiac surgery and anticoagulated with argatroban is greater than with anticoagulation using UH.

Previous studies have been published on intermittent dialysis and argatroban for critically ill patients, ${ }^{14}$ for the evaluation of bleeding and thrombotic risk after cardiac 

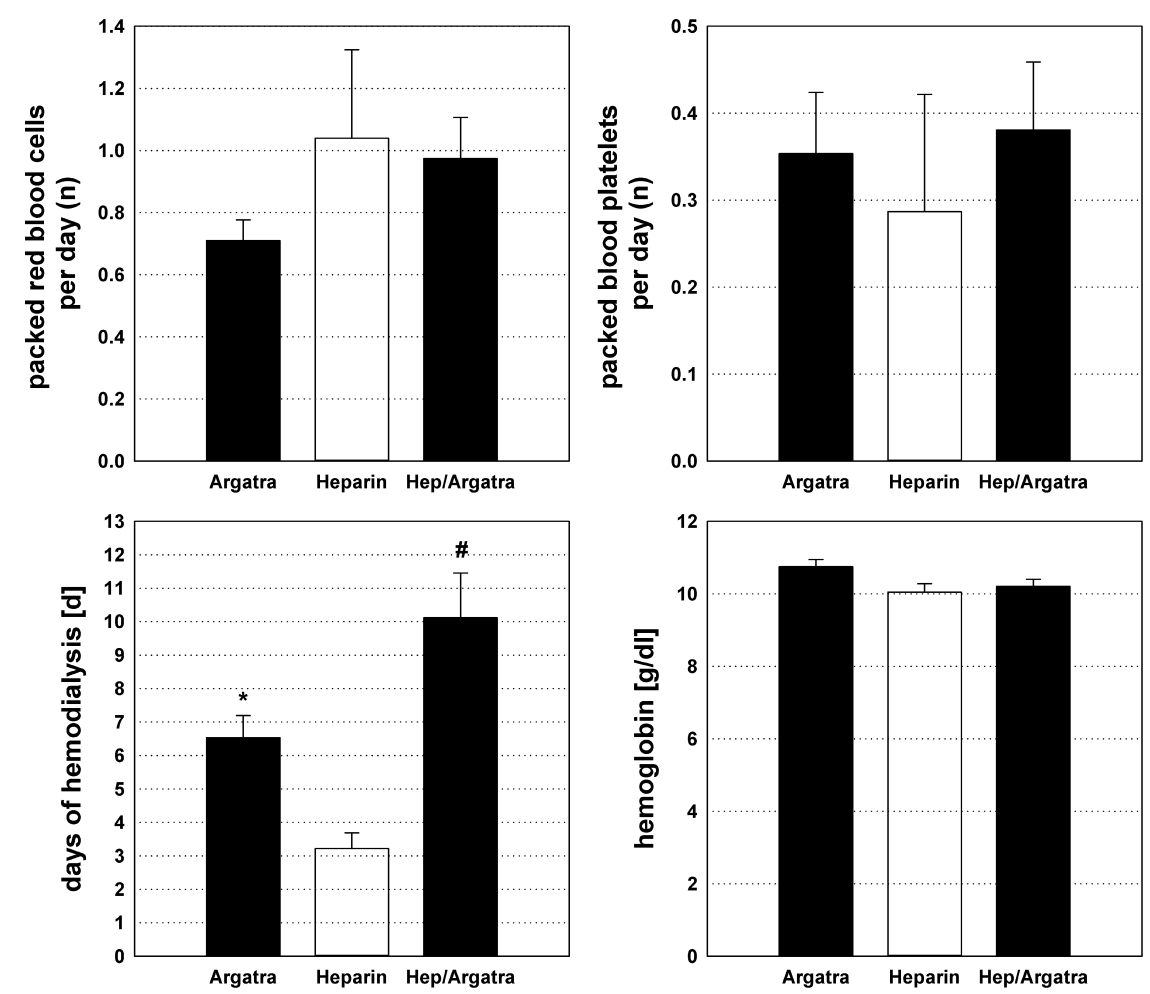

FIGURE 2. Need for transfusion daily, duration of dialysis, and hemoglobin during dialysis period in patients receiving argatroban or heparin or who were switched from heparin to argatroban.

surgery in patients with suspected or proven HIT II, ${ }^{13,17}$ and for the evaluation of argatroban dosing in patients with multiple organ dysfunction, ${ }^{8,15}$ with $31,{ }^{13} 47,{ }^{17} 30,{ }^{8}$ and $12^{15}$ patients, respectively. Such studies were limited by small patient numbers and did not directly compare treatment with argatroban against heparin. The present study considered 41 postoperative critical care patients receiving continuous RRT and anticoagulation with argatroban, making it the largest evaluation of its kind to date.

\section{Choice of Anticoagulation and HIT II}

$\mathrm{UH}$ is the most commonly used anticoagulant for continuous RRT. ${ }^{4}$ In the present study period, UH was used as the standard form of anticoagulation for RRT at our center. Although dialysis was started within a median postoperative period of 2.0 days, in 41 patients, a clinical

TABLE 2. Need for transfusion per day during continuous venovenous hemodialysis

\begin{tabular}{lccc}
\hline & \multicolumn{2}{c}{ UH conversion to argatroban } & \\
\cline { 2 - 3 } \multicolumn{1}{c}{ Transfusion } & $\begin{array}{c}\mathbf{U H} \\
(\mathbf{n}=\mathbf{2 6})\end{array}$ & $\begin{array}{c}\text { Argatroban } \\
(\mathbf{n}=\mathbf{2 6})\end{array}$ & $\begin{array}{c}\boldsymbol{P} \\
\text { value }\end{array}$ \\
\hline Packed RBC/d (U) & $1.2 \pm 0.3$ & $1.0 \pm 0.1$ & .32 \\
Packed blood platelets/d (U) & $0.3 \pm 0.1$ & $0.4 \pm 0.1$ & .62 \\
\hline
\end{tabular}

$R B C$, Red blood cell; $U H$, unfractionated heparin. suspicion of HIT II arose because of a decline in platelets that could not be explained by the cardiopulmonary bypass or evidence of thrombosis or embolism, as suggested by Lo and colleagues. ${ }^{18}$ Most of these patients had received heparin-based anticoagulation before surgery, supporting a clinical suspicion of HIT II. This-at least in part-explains why dialysis was started with argatroban in 41 patients, which might otherwise have appeared excessive. With a clinical suspicion of HIT II and no method of absolutely excluding such a diagnosis, it was thought safer to avoid anticoagulation with UH postoperatively. HIT II was confirmed in $7 \%$ of patients starting with argatroban. HIT II was later confirmed in $15 \%$ of patients receiving $\mathrm{UH}$ and switched to argatroban.

Anticoagulation with citrate offers a possible alternative in cases of HIT II. Although the efficacy and safety of regional citrate anticoagulation has largely been described, its diffusion appears relatively limited, ranging from about $10 \%$ (Beginning and Ending Supportive Therapy for the Kidney [BEST] study) ${ }^{8}$ to $20 \%$ (Acute Renal Failure Trial Network study) ${ }^{16}$ in continuous RRT. In our center, the use of citrate for anticoagulation during RRT before 2010 was rather limited owing to initial technical limitations. Thus, citrate was only used in a few patients with ongoing or severe bleeding complications within the postoperative phase, where RRT was deemed necessary and the anticoagulation regimen for RRT was changed on several occasions. 


\section{Anticoagulation Efficacy}

Sufficient anticoagulation is essential in dialysis to minimize coagulation within the extracorporeal circuit. However, achieving adequate anticoagulation can be complicated by factors such as HIT, extracorporeal circuit clotting, and changes in the RRT anticoagulant requirements over time. Thus maintaining continuous RRT for several days is challenging, with anticoagulation monitoring and dosage further complicated in treating critically ill patients with the potential to develop hepatic impairment or multiorgan failure.

Inadequate anticoagulation within the extracorporeal unit will result in higher filter requirements. ${ }^{4}$ A comparison among the 3 groups showed a mean requirement of 1.1 filters/day of dialysis (Table 1). Close monitoring of anticoagulation allowed maintenance of the activated partial thromboplastin time within the desired therapeutic range of 60 to 90 seconds. This combination of laboratory monitoring and longevity of the circuit filters between the groups treated with argatroban indirectly suggested comparably effective anticoagulation.

\section{Blood Loss}

Transfusion rates of $10 \%$ to $60 \%$ for patients after cardiac surgery have previously been reported. ${ }^{20,21}$ Transfusion was undertaken in all patients for whom hemoglobin was $<9.5 \mathrm{~g} / \mathrm{dL}$, with the intention of maintaining hemoglobin at $>10 \mathrm{~g} / \mathrm{dL}$. Although the guidelines specify an initial transfusion at lower hemoglobin levels, ${ }^{22}$ evidence has also been presented in support of early transfusion. ${ }^{23}$

Anticoagulation during RRT can lead to increased blood loss postoperatively. However, no evidence was observed clinically within the present study to support this. Furthermore, the transfusion requirements to maintain hemoglobin levels at or $>10 \mathrm{~g} / \mathrm{dL}$ during RRT were the same, indirectly excluding any clinically relevant bleeding. The hemoglobin values can vary with shifts in fluid volume, which in the present context need not be associated with bleeding. By maintaining a comparably consistent volume balance among the groups, the effect of this factor was negated. Clotting within the filter and extracorporeal circuit with subsequent disposal can result in blood loss of around $250 \mathrm{~mL}$. In our evaluation, the requirement for filter changes remained constant at 1.1/dialysis day. Two conclusions can be inferred from this finding: the anticoagulation was adequate and thus no difference resulted in blood loss secondary to the filter changes among the 3 groups. Furthermore, the changes in hemoglobin levels did not result from dilution as a consequence of relevant differences in the fluid balances. The direct influence of the anticoagulant on patient transfusion requirements could be seen in those requiring conversion from heparin to argatroban (Table 1). No statistically significant difference was noted between argatroban and UH. This was related to a tendency for reduced postoperative transfusion requirements over time, rather than problems relating to the correct anticoagulation dosage.

\section{Bleeding Risk}

Comparing the laboratory findings, no significant difference was observed among the 3 groups. Although some patients showed signs of hepatic impairment, with elevated bilirubin and reduced cholinesterases at dialysis initiation, the incidence of bleeding complications remained comparable among the 3 groups. Despite the hepatic dysfunction significantly prolonging the half-life of argatroban, the incidence of bleeding did not increase. .,26 $^{8}$ We appreciate this was likely a result of close monitoring and dose adjustment, as previously described in published studies. $^{8,26,27}$

Some nonsignificant differences by gender (male $83 \%$ vs female $54 \%$ ) and age (70 vs 74 years) were noted between the 2 groups, with the argatroban group on average older than the UH group. In agreement with the few previous publications in this field, we found no association between patient age and the risk of bleeding with argatroban. ${ }^{27}$ Although the severity of disease (SAPS II) at the start of RRT was not statistically significant, patients exclusively receiving argatroban or converted to argatroban from UH tended to start dialysis with a higher SAPS II score. During the dialysis period, the maximal SAPS II score increased in these 2 groups from 44 to 54 and 55, but remained almost unchanged in the UH-only group (SAPS II, 41 or 43). Despite the increasing disease severity, no bleeding complications developed. We attributed this to the rapid adjustment of the argatroban dosage, as described in other studies. $^{8,13,15}$

\section{Outcome and Mortality}

The outcome and mortality in our study was comparable to that of other studies, because the postoperative morbidity and mortality has been significantly greater in patients who develop AKI after cardiac surgery. ${ }^{2,28,29}$

Patients receiving UH had a longer overall inpatient stay, despite a reduced intensive care stay (8 vs 11 days) and dialysis requirements, potentially accounted for by differences in morbidity and outcome. A higher SAPS II score was equated with greater mortality and thus a shorter length of stay. The patients initially receiving argatroban had a higher maximal SAPS II score and mortality than those receiving UH alone (44\% vs $71 \%)$. We assumed that this could account for the observed differences in fluid balance. An association between a positive fluid balance and greater mortality has been supported by several studies. ${ }^{24,25}$ Furthermore, by having a higher maximal SAPS II score, factors such as patient age at baseline, a known confounding variable in postoperative mortality after 
cardiac surgery, ${ }^{30}$ likely influenced the probability of developing postoperative complications. No mortality secondary to bleeding complications was observed. Thus, the outcomes and mortality were less associated with mode of anticoagulation during RRT than with age or disease severity.

\section{Study Limitations}

The significance of the study results was limited by the comparatively small group sizes. Furthermore, variations in the baseline cardiac pathology and the intraoperative procedure undertaken complicated the standardization, even if no statistically significant difference was found. One particular concern was related to the clinical judgment of bleeding and the basis for transfusion. The rapid initiation of postoperative RRT can be associated with dialysis-associated blood loss, creating confusion regarding whether the blood loss was associated with RRT or secondary to the surgical insult. This concern can only be partially resolved by knowing that the median day of dialysis initiation was the same, irrespective of the group (day 2) and therefore that effect was comparable, regardless of the anticoagulant used.

\section{CONCLUSIONS}

Argatroban can provide effective anticoagulation in postoperative cardiac patients receiving continuous RRT within an intensive care setting. Close monitoring and dose titration results in a comparable risk of bleeding with anticoagulation using either argatroban or heparin, regardless of the underlying disease severity or hepatic impairment.

\section{References}

1. Hoste EA, Cruz DN, Davenport A, Mehta RL, Piccinni P, Tetta C, et al The epidemiology of cardiac surgery-associated acute kidney injury. Int J Artif Organs. 2008;31:158-65.

2. Ronco C, Kellum JA, Bellomo R. Cardiac surgery-associated acute kidney injury. Int J Artif Organs. 2008;31:156-7.

3. Shaw A. Update on acute kidney injury after cardiac surgery. J Thorac Cardiovasc Surg. 2012;143:676-81.

4. Ostermann M, Dickie H, Tovey L, Treacher D. Heparin algorithm for anticoagulation during continuous renal replacement therapy. Crit Care. 2010; $14: 419$.

5. Levy JH, Winkler AM. Heparin-induced thrombocytopenia and cardiac surgery. Curr Opin Anaesthesiol. 2010;23:74-9.

6. Everett BM, Yeh R, Foo SY, Criss D, Van Cott EM, Laposata M, et al. Prevalence of heparin/platelet factor 4 antibodies before and after cardiac surgery. Ann Thorac Surg. 2007;83:592-7.

7. Koster A, Hentschel T, Groman T, Kuppe H, Hetzer R, Harder S, et al. Argatroban anticoagulation for renal replacement therapy in patients with heparin-induced thrombocytopenia after cardiovascular surgery. J Thorac Cardiovasc Surg. 2007;133:1376-7.

8. Uchino S, Bellomo R, Morimatsu H, Morgera S, Schetz M, Tan I, et al. Continuous renal replacement therapy: a worldwide practice survey. The beginning and ending supportive therapy for the kidney (B.E.S.T. kidney) investigators. Crit Care Med. 2007;33:1563-70.
9. Hijikata-Okunomiya A, Okamoto S. A strategy for a rational approach to designing synthetic selective inhibitors. Semin Thromb Hemost. 1992;18: 135-49.

10. Walenga JM. An overview of the direct thrombin inhibitor argatroban. Pathophysiol Haemost Thromb. 2002;32(Suppl 3):9-14.

11. Walenga JM, Ahmad S, Hoppensteadt D, Iqbal O, Hursting MJ, Lewis BE. Argatroban therapy does not generate antibodies that alter its anticoagulant activity in patients with heparin-induced thrombocytopenia. Thromb Res. 2002; 105:401-5.

12. Keegan SP, Ernst NE, Mueller EW. Argatroban for anticoagulation in continuous renal replacement therapy. Crit Care Med. 2009;37:2139-40.

13. Yoon JH, Yeh RW, Nam KH, Hoffman WD, Agnihotri AK, Jang IK. Safety and efficacy of the argatroban therapy during the early post-cardiac surgery period. J Thromb Thrombol. 2010;30:276-80.

14. Sun X, Chen Y, Xiao Q, Wang Y, Zhou J, Ma Z, et al. Effects of argatroban as an anticoagulant for intermittent veno-venous hemofiltration (IVVH) in patients at high risk of bleeding. Nephrol Dial Transplant. 2011;26:2954-9.

15. Saugel B, Phillip V, Moessmer G, Schmid RM, Huber W. Argatroban therapy for heparin-induced thrombocytopenia in ICU patients with multiple organ dysfunction syndrome: a retrospective study. Crit Care. 2010;14:R90.

16. Mehta RL, Kellum JA, Shah SV, Molitoris BA, Ronco C, Warnock DG, et al. Acute Kidney Injury Network: report of an initiative to improve outcomes in acute kidney injury. Crit Care. 2007;11:R31.

17. Demma LJ, Paciullo CA, Levy JH. Recognition of heparin-induced thrombocytopenia and initiation of argatroban therapy after cardiothoracic surgery in the intensive care unit. J Thorac Cardiovasc Surg. 2012;143: 1213-8.

18. Lo GK, Juhl D, Warkentin TE, Sigouin CS, Eichler P, Greinacher A. Evaluation of pretest clinical score (4 T's) for the diagnosis of heparininduced thrombocytopenia in two clinical settings. J Thromb Haemost. 2006; 4:759-65.

19. Reddy BV, Grossman EJ, Trevino SA, Hursting MJ, Murray PT. Argatroban anticoagulation in patients with heparin-induced thrombocytopenia requiring renal replacement therapy. Ann Pharmacother. 2005;39:1601-5.

20. Andreasen JJ, Westen M, Pallesen PA, Jensen S, Gorst-Rasmussen A, Johnsen SP. Transfusion practice in coronary artery bypass surgery in Denmark: a multicenter audit. Interact Cardiovasc Thorac Surg. 2007;6:623-7.

21. Schiferer A, Panzer S, Reesink HW, Baulig W, Bélisle S, Gerrard C, et al. Red cell transfusion in elective cardiac surgery patients. Vox Sang. 2009;97: 172-82.

22. Society of Thoracic Surgeons Blood Conservation Guideline Task Force, Ferraris VA, Brown JR, Despotis GJ, Hammon JW, Reece TB, et al. 2011 update to the Society of Thoracic Surgeons and the Society of Cardiovascular Anesthesiologists blood conservation clinical practice guidelines. Ann Thorac Surg. 2011;91:944-82.

23. Atasever B, van der Kuil M, Boer C, Vonk A, Schwarte L, Girbes AR, et al. Red blood cell transfusion compared with gelatin solution and no infusion after cardiac surgery: effect on microvascular perfusion, vascular density, hemoglobin, and oxygen saturation. Transfusion. 2012;52:2452-8.

24. Bagshaw SM, Brophy PD, Cruz D, Ronco C. Fluid balance as a biomarker: impact of fluid overload on outcome in critically ill patients with acute kidney injury. Crit Care. 2008;12:169.

25. Payen D, de Pont AC, Sakr Y, Spies C, Reinhart K, Vincent JL. A positive fluid balance is associated with a worse outcome in patients with acute renal failure. Crit Care. 2008;12:R74.

26. Beiderlinden M, Treschan TA, Gorlinger K, Peters J. Argatroban anticoagulation in critically ill patients. Ann Pharmacother. 2007;41:749-54.

27. Bartholomew JR, Pietrangeli CE, Hursting MJ. Argatroban anticoagulation for heparin-induced thrombocytopenia in elderly patients. Drugs Aging. 2007;24: 489-99.

28. Ellenberger C, Schweizer A, Diaper J, Kalangos A, Murith N, Katchatourian G, et al. Incidence, risk factors and prognosis of changes in serum creatinine early after aortic abdominal surgery. Intensive Care Med. 2006;32:1808-16.

29. Hobson CE, Yavas S, Segal MS, Schold JD, Tribble CG, Layon AJ, et al. Acute kidney injury is associated with increased long-term mortality after cardiothoracic surgery. Circulation. 2009;119:2444-53.

30. Weiler N, Waldmann J, Bartsch DK, Rolfes C, Fendrich V. Outcome in patients with long-term treatment in a surgical intensive care unit. Langenbecks Arch Surg. 2012;397:995-9. 